\title{
Nonsteroidal anti-inflammatory drugs for heavy menstrual bleeding (Review)
}

\author{
Lethaby A, Augood C, Duckitt K
}

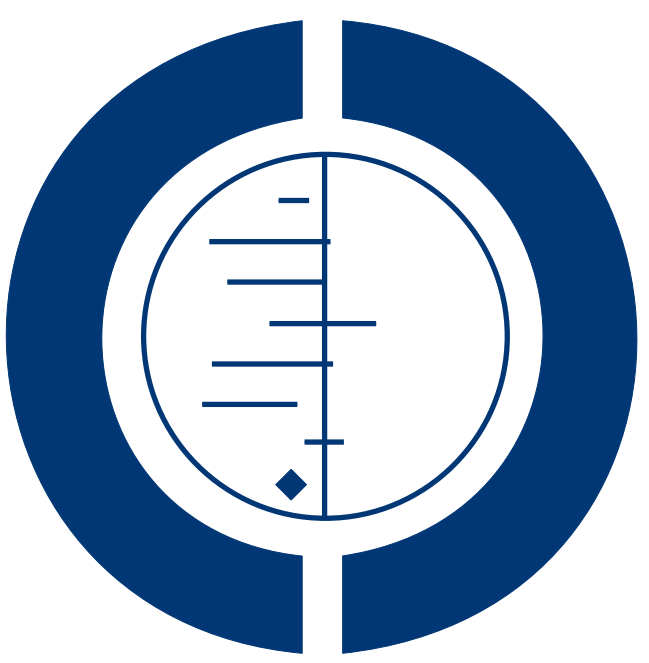

THE COCHRANE
COLLABORATION $^{\circledR}$

This is a reprint of a Cochrane review, prepared and maintained by The Cochrane Collaboration and published in The Cochrane Library 1998, Issue 3

http://www.thecochranelibrary.com

\section{WILEY}

Nonsteroidal anti-inflammatory drugs for heavy menstrual bleeding (Review)

Copyright @ 2007 The Cochrane Collaboration. Published by John Wiley \& Sons, Ltd. 
TABLE OF CONTENTS

HEADER . . . . . . . . . . . . . . . . . . . . . . . . . . . . . . . . . . . . . . . . 1

ABSTRACT . . . . . . . . . . . . . . . . . . . . . . . . . . . . . . . . . . . . . . . . . . . . . . .

PLAIN LANGUAGE SUMMARY . . . . . . . . . . . . . . . . . . . . . . . . . . . . . . . . . . . 2

BACKGROUND . . . . . . . . . . . . . . . . . . . . . . . . . . . . . . . . . . . . . .

OBJECTIVES . . . . . . . . . . . . . . . . . . . . . . . . . . . . . . . . . . . . . .

RESULTS . . . . . . . . . . . . . . . . . . . . . . . . . . . . . . . . . . . . . . .

DISCUSSION . . . . . . . . . . . . . . . . . . . . . . . . . . . . . . . . . . . . . . 4

AUTHORS' CONCLUSIONS . . . . . . . . . . . . . . . . . . . . . . . . . . . . . . . 5

ACKNOWLEDGEMENTS . . . . . . . . . . . . . . . . . . . . . . . . . . . . . . . . . . . . . . 6

REFERENCES . . . . . . . . . . . . . . . . . . . . . . . . . . . . . . . . . . . . . 6

SOURCES OF SUPPORT . . . . . . . . . . . . . . . . . . . . . . . . . . . . . . . . . . . . . . . .

NOTES . . . . . . . . . . . . . . . . . . . . . . . . . . . . . . . . . . . . . . . 8

INDEX TERMS . . . . . . . . . . . . . . . . . . . . . . . . . . . . . . . . . . . . 8

Nonsteroidal anti-inflammatory drugs for heavy menstrual bleeding (Review)

Copyright $\odot 2007$ The Cochrane Collaboration. Published by John Wiley \& Sons, Ltd. 


\title{
[Intervention Review] \\ Nonsteroidal anti-inflammatory drugs for heavy menstrual bleeding
}

\author{
A Lethaby, C Augood, K Duckitt \\ Contact address: Ms Anne Lethaby, Section of Epidemiology and Biostatistics (Level four), School of Population Health, Tamaki \\ Campus, University of Auckland, Private Bag 92019, Auckland, NEW ZEALAND. a.lethaby@auckland.ac.nz.
}

Editorial group: Cochrane Menstrual Disorders and Subfertility Group.

Publication status and date: Unchanged, published in Issue 3, 2007.

Review content assessed as up-to-date: .

Citation: Lethaby A, Augood C, Duckitt K. Nonsteroidal anti-inflammatory drugs for heavy menstrual bleeding. Cochrane Database of Systematic Reviews 1998, Issue 3. Art. No.: CD000400. DOI: 10.1002/14651858.CD000400.

Copyright (C) 2007 The Cochrane Collaboration. Published by John Wiley \& Sons, Ltd.

\begin{abstract}
A B S T R A C T
Background

Heavy menstrual bleeding (HMB) is an important cause of ill health in premenopausal women. Although surgery is often used as a treatment, a range of medical therapies are also available. Nonsteroidal anti-inflammatory drugs reduce prostaglandin levels which are elevated in women with excessive menstrual bleeding and also may have a beneficial effect on dysmenorrhoea.
\end{abstract}

\section{Objectives}

The primary objective of this review was to investigate the effectiveness of non-steroidal anti-inflammatory drugs (NSAIDs) in achieving a reduction in menstrual blood loss in women of reproductive years HMB.

\section{Search strategy}

We searched the Cochrane Menstrual Disorders \& Subfertility Group trials register (searched 6 April 2004), the Cochrane Central Register of Controlled Trials (CENTRAL) (The Cochrane Library, Issue 1, 2004), MEDLINE (1966 to April 2004), EMBASE (1985 to April 2004), CINAHL (1982 to April 2004), and Current Contents (1993 to April 2004) and reference lists of articles. We also contacted manufacturers and researchers in the field.

\section{Selection criteria}

The inclusion criteria were randomised comparisons of individual NSAIDs with either each other, placebo or other medical treatments in women with regular heavy periods measured either objectively or subjectively and with no pathological or iatrogenic (treatment induced) causes for their heavy menstrual blood loss.

\section{Data collection and analysis}

Sixteen RCTs were identified that fulfilled the inclusion criteria for this review and data were extracted independently. Odds ratios for dichotomous outcomes and weighted mean differences for continuous outcomes were estimated from the data of nine trials. The results of the remaining seven crossover trials with data unsuitable for pooling were described in the Other Data section.

\section{Main results}

As a group, NSAIDs were more effective than placebo at reducing heavy menstrual bleeding but less effective than either tranexamic acid or danazol. Treatment with danazol caused a shorter duration of menstruation and more adverse events than NSAIDs but this did not appear to affect the acceptability of treatment. There were no statistically significant differences between NSAIDs and the other

Nonsteroidal anti-inflammatory drugs for heavy menstrual bleeding (Review)

Copyright @ 2007 The Cochrane Collaboration. Published by John Wiley \& Sons, Ltd. 
treatments (oral luteal progestogen, ethamsylate, progesterone releasing intra-uterine system (IUS), oral contraceptive pill (OCC)) but most studies were underpowered. There was no evidence of a difference between the individual NSAIDs (naproxen and mefenamic acid) in reducing HMB.

\section{Authors' conclusions}

NSAIDs reduce HMB when compared with placebo but are less effective than either tranexamic acid or danazol. However, adverse events are more severe with danazol therapy. In the limited number of small studies suitable for evaluation, no significant difference in efficacy was demonstrated between NSAIDs and other medical treatments such as oral luteal progestogen, ethamsylate, OCC or IUS.

\section{PLAIN LANGUAGE SUMMARY}

NSAIDs help reduce heavy menstrual bleeding but tranexamic acid or danazol work better.

Women seek help for heavy menstrual bleeding (HMB) when it impacts on their quality of life although the menstrual loss can be assessed objectively. Levels of prostaglandin (naturally occurring fatty acids) are higher in women with heavy menstrual bleeding and are reduced by nonsteroidal anti-inflammatory drugs (NSAIDs). The review of trials found that NSAIDs are effective in reducing HMB but danazol and tranexamic acid are more effective. Danazol caused a shorter duration of bleeding and more adverse effects than NSAIDs but this did not stop women using it. These results are based on a small number of underpowered trials.

\section{B A C K G R O U N D}

Excessively heavy menstrual bleeding (menorrhagia) is an important cause of ill health in women. One in 20 women aged 30 to 49 consult their general practitioner (GP) each year with heavy menstrual bleeding (Vessey 1992) and it accounts for 12\% of all gynaecology referrals in the UK (Bradlow 1992).

Heavy menstrual bleeding is objectively defined as greater than, or equal to, $80 \mathrm{mls}$ blood loss per menstrual cycle (Cole 1971; Hallberg 1966) but it is the woman's perception of her own menstrual loss which is the key determinant in her referral and indeed subsequent treatment. Many factors can cause abnormal menstruation (coagulation disorders, endocrine disorders, uterine abnormalities and other pelvic diseases) and these disorders are usually considered before decisions are made about treatment. Eighty per cent of women treated for heavy menstrual bleeding have no anatomical pathology and over a third of the women undergoing hysterectomies for excessive blood loss have normal uteri removed (Clarke 1995; Gath 1982). Hence medical therapy, with the avoidance of possibly unnecessary surgery, is an attractive alternative.

A wide variety of medications are used to reduce heavy menstrual bleeding (HMB). A rationale for the use of non-steroidal anti-inflammatory drugs is given by the accumulation of data suggesting a role for the prostaglandins in the pathogenesis of HMB (Hagenfeldt 1987). The endometrium of women with excessive menstrual bleeding has been found to have higher levels of prostaglandin E2 and prostaglandin F2a when compared with women with normal menses (Willman 1976). There is further evidence of deranged haemostasis (abnormal clotting) as the ratio of prostaglandin E2 to F2 (Smith 1981) and the ratio of prostacyclin (prostaglandin I2) to thromboxane (Makarainen 1986) are elevated. These substances are present both in the endometrium and myometrium, although the exact mechanism by which the excessive blood loss occurs remains speculative. Nonsteroidal antiinflammatory drugs (NSAIDs) reduce prostaglandin levels by inhibiting the enzyme cyclo-oxygenase (Rees 1987; Smith 1981). In 1976, Anderson reported a reduction of menstrual blood loss when mefenamic acid and flufenamic acid were taken during the days of menstrual bleeding (Anderson 1976). Reduced menstrual loss (assessed subjectively) has also been reported after treatment with mefenamic acid (Wood 1980).

Individual NSAIDs used for the treatment of heavy menstrual bleeding include mefenamic acid, naproxen, ibuprofen, flurbiprofen, meclofenamic acid, diclofenac, indomethacin and acetylsalicylic acid. It is usually assumed that there are no differences in clinical efficacy between individual prostaglandin inhibitors, although there are individual women who seem to respond well to one agent but less well to another. This assumption has been tested in the review with the inclusion of individual NSAID comparisons for the treatment of HMB. NSAIDs also can have a beneficial effect on dysmenorrhoea, a symptom often related to heavy menstrual bleeding. Side effects of treatment, especially gastro-intestinal ef- 
fects, are variable in frequency but are not usually severe.

\section{O B J E C T I V E S}

To determine the effectiveness of NSAIDs in achieving a reduction in menstrual blood loss in women of reproductive years with heavy menstrual bleeding.

We wished to test the following hypotheses:

(1) Treatment with NSAIDs is more effective than placebo in reducing menstrual blood loss.

(2) Treatment with NSAIDs is more effective than other medical therapies (anti-fibrinolytics, danazol, hormone treatment, LHRH/ GNRH analogues) in reducing menstrual blood loss.

(3) Individual NSAIDs have similar efficacy in reducing menstrual blood loss.

(4) Treatment with NSAIDs is associated with a lower incidence of adverse events and higher adherence and greater acceptability than other medical therapies.

(5) Treatment with NSAIDs is a cost-effective method of treating heavy menstrual bleeding.

(6) Treatment with NSAIDs leads to an improved quality of life for women with heavy menstrual bleeding (in particular, an improvement in symptoms of dysmenorrhoea).

\section{R E S U L T S}

\section{NSAIDs versus placebo}

\section{Menstrual blood loss (objective/subjective)}

Mean menstrual blood loss was significantly different in the mefenamic acid (MFA) group compared to the placebo group in one small trial with 11 patients (WMD -124 mls, 95\% CI -186 to 62) in the meta-analysis (MBL in the MFA group was $124 \mathrm{mls}$ less than in the placebo group). There were no other trials with data suitable for pooling but six crossover trials were identified which reported a total effect at the end of the study (three trials compared mefenamic acid with placebo, two trials compared naproxen with placebo and one trial compared different dosages ( $600 \mathrm{mg}$ and $1200 \mathrm{mg}$ daily) of ibuprofen with placebo). In five of the seven post-treatment comparisons, the post-treatment mean MBL was significantly different from placebo. However, non significant results were also reported for low dose ibuprofen versus placebo (Makarainen 1986) and mefenamic acid versus placebo (Muggeridge 1983).

A highly significant difference was found in womens' perception of “relief” (OR 0.08, 95\% CI 0.03 to 0.18 ) of heavy menstrual bleeding between mefenamic acid and placebo groups (Grover 1990).
No additional information was made available from the author regarding the measurement of relief of HMB. In one of the crossover trials not included in the meta-analysis (Ylikorkala 1986), 79\% of patients indicated that naproxen was "better" compared to $21 \%$ who indicated that the placebo treatment was "better" at reducing their HMB.

\section{Other outcomes}

No trials were identified for the meta-analysis to assess number of days of menstrual bleeding, change in quality of life, patient adherence and treatment acceptability. In the small van Eijkeren study, total incidence of adverse events was comparable between groups, mefenamic acid and placebo (van Eijkeren 1992). Of the crossover trials identified above, there was no change in dysmenorrhoea scores between treatment cycles, mefenamic acid vs placebo, (Muggeridge 1983), and no differences in the total incidence of adverse events between treatment cycles, naproxen vs placebo and ibuprofen vs placebo (Ylikorkala 1986; Makarainen 1986).

NSAIDs versus tranexamic acid

\section{Menstrual blood loss (objective/subjective)}

In the one study available for pooling with 48 patients, a weighted mean difference of $73 \mathrm{ml} /$ cycle (95\% CI 22 to 124 ) was found in the comparison of mefenamic acid and tranexamic acid (MBL in the tranexamic acid group was $73 \mathrm{ml}$ less than in the mefenamic acid group). In the same study, there was no significant difference between the groups in the womens' perception of change in their MBL. In a crossover trial, where data were not suitable for pooling, mean MBL was significantly less in the tranexamic acid cycles (155 $\mathrm{ml}$ ) than in the flurbiprofen cycles $(223 \mathrm{ml}), \mathrm{p}<0.01$ (Andersch 1988).

\section{Number of days of menstrual bleeding}

In the one study available for pooling, there were no significant differences between treatment groups.

\section{Other outcomes}

No significant differences were found between groups for the outcomes, change in quality of life and treatment acceptability, although these results were based on only one study. No trials were identified to assess the other outcomes.

\section{NSAIDs versus ethamsylate}

All outcomes, except for MBL measured objectively, were based on only one study.

\section{Menstrual blood loss (objective/subjective)}

No significant differences were found for both objective (two studies) and subjective measurement (one study) of MBL between the treatment groups, immediately after the intervention and at longer follow up (one study).

\section{Number of days of menstrual bleeding}


In the one study available for pooling, no significant differences were found for this outcome between treatment groups.

\section{Other outcomes}

In the one study available for pooling, no significant differences were found between treatment groups for the secondary outcome, change in quality of life, but a greater proportion of women found ethamsylate unacceptable compared to NSAIDs (OR 0.20, 95\% CI 0.07 to 0.61 ). No trials were identified to assess the other outcomes.

\section{NSAIDs versus danazol}

\section{Menstrual blood loss (objective)}

Reduction of HMB was significantly greater in the danazol group (WMD $45 \mathrm{ml} /$ cycle, 95\% CI 19 to 71 ). No trials were identified which assessed womens' perception of MBL after treatment.

\section{Number of days of menstrual bleeding}

The number of days of menstrual bleeding was significantly less in the danazol compared to the mefenamic acid groups (WMD $1.03,95 \%$ CI 0.26 to 1.80 ).

\section{Other outcomes}

No significant differences were found for the outcomes, change in quality of life and treatment acceptability between groups, although these results were based on one study with 40 patients. In this same study, the risk of adverse events was significantly less in the mefenamic acid group (OR $0.17,95 \%$ CI 0.05 to 0.6 ).

\section{NSAIDs versus oral progestogen (luteal phase)}

Two studies assessed MBL and duration of bleeding and one study with 35 patients assessed adherence and adverse events. No significant differences were found for any outcomes.

\section{NSAIDs versus progesterone releasing IUS}

Reduction of HMB was not significantly different between groups in one small trial with 16 patients but the number of days of menstrual bleeding was significantly longer in patients with the progesterone releasing IUS.

\section{NSAIDs versus oral contraceptive pill}

In the one study with data suitable for pooling (26 patients), no significant differences were found in the objective measurement of MBL between treatment groups. No other outcomes were assessed.

\section{Mefenamic acid versus naproxen}

No significant differences were found in the objective measurement of MBL (two studies) and total incidence of adverse events between treatment groups (one study), but the risk of gastrointestinal effects was significantly less in the mefenamic acid group when compared with the naproxen group in one study with 35 patients (OR 0.24 , 95\% CI 0.06 to 0.87 ).

\section{DISCUSSION}

Assessment of menstrual blood loss is difficult because of cycle to cycle variation in women (Haynes 1977). Haynes found that cycle-to-cycle variation was greater in patients with heavy menstrual bleeding (39 to $271 \mathrm{ml}$ ) than in women with normal menses. Consequently, trials were included in this review only if MBL (measured objectively) was greater than $80 \mathrm{ml} /$ cycle for 2 or more cycles prior to the intervention although trials were also included where women had a subjective complaint of heavy menstrual bleeding. The alkaline haematin extraction method is the most commonly used objective method for assessment of blood loss and is used as the standard but a woman's own perception of her MBL is also important in the evaluation of effectiveness of treatment on MBL and so a woman's subjective assessment is also a valid assessment tool. However, many women who seek medical help for heavy menstrual bleeding will have normal blood loss (Haynes 1977; Fraser 1984) and results from one RCT have suggested that there is little response to therapy in women with $\mathrm{MBL}<35 \mathrm{ml}$ (Fraser 1981). Since a proportion of the study participants with a complaint of heavy menstrual bleeding had normal menstrual blood loss, it is likely that some reported differences between treatment and placebo groups have been underestimated.

The clinical differences between individual NSAID preparations have not been previously explored thoroughly in randomised studies. Two studies in this review compared mefenamic acid with naproxen and no differences were found in post-treatment menstrual blood loss or incidence of adverse events although women treated with mefenamic acid were less likely to have gastro-intestinal effects. This latter finding, however, based on only one trial, is not supported by RCTs where NSAIDs are given for other medical conditions.

Although data comparing different types of NSAIDs were limited, there was no suggestion of differential efficacy, so in line with the widely accepted assumption that NSAIDs have similar clinical efficacy, studies comparing different NSAIDs with placebo or other treatments were combined. Evidence from the one trial in the meta-analysis and five of the six crossover studies confirms that NSAIDs are more effective than placebo in reducing MBL. The quality of the only study in the meta-analysis, however, was not high; $42 \%$ of randomised patients dropped out and the analysis was not intention to treat. A highly significant difference between NSAIDs and placebo in reduction of MBL is also perceived by the patients in one study which recorded the proportion of patients who were relieved of their heavy menstrual bleeding as the primary outcome.

In the comparisons of NSAIDs as a group with other medical treatments, both tranexamic acid and danazol were more effective than any of the NSAIDs in reducing MBL. Results from the only study in the meta-analysis assessing the effect on MBL of NSAIDs vs tranexamic acid were confirmed by a crossover trial 
(Andersch 1988). A significant reduction was also found in the meta-analysis of NSAIDs vs danazol in two included studies; the third study (Cameron 1987) had incomparable groups at baseline with a significantly higher (almost double) pre-treatment MBL in the danazol group and the results must be regarded with caution.

There were no significant differences in reduction of MBL in the comparisons of NSAIDs with ethamsylate, oral progestogen given during the luteal phase, the progesterone releasing IUS and the oral contraceptive pill, although the trend in the mefenamic acid vs ethamsylate comparison and the mefenamic acid vs oral progestogen comparison suggested that mefenamic acid may be more effective ( $\mathrm{p}=0.0524 ; \mathrm{p}=0.0562$ ). More studies comparing these treatments are needed.

In the comparisons of NSAIDs with other medical treatment, the number of days of menstrual bleeding was significantly shorter with danazol treatment and significantly longer with the progesterone releasing IUS although this latter result was based on only one small trial. This outcome was not compared with oral contraceptive treatment.

Incidence of adverse events was significantly more likely under danazol treatment. Although acceptability of treatment did not differ between danazol and mefenamic acid therapy ( $50 \%$ vs $47 \%$ refused to continue), the reasons given were not similar. $80 \%$ of this group of danazol patients refused to continue because of adverse effects but $100 \%$ of the mefenamic acid group unwilling to continue were unhappy about the lack of efficacy of their treatment. A significantly greater proportion of women in the ethamsylate group compared to women in the NSAID group (MFA) found their treatment unacceptable.

No trials were identified with data on cost or resource use of NSAID treatments.

The studies included in this review have examined effects over two or three menstrual cycles of treatment and one study with unpublished data has assessed effects one month after treatment was withdrawn. There is no randomised evidence of effects over a longer period but one observational study has examined the effects of mefenamic acid in 34 women over a 16 month period and reported persistent reductions of $25-35 \%$ in menstrual blood loss and improvement in quality of life (Fraser 1983).

Moreover, different dosage regimens for some of the medical therapies were not considered in the included trials. A longer duration of oral progestogen treatment (from days 5 to 26 of the menstrual cycle), and longer duration of treatment over a number of cycles with all medical therapies are necessary to adequately assess the comparisons considered in this review.

Although 16 trials met the criteria for inclusion, the inadequacies in some of the studies must be highlighted. The trials were all small and underpowered and for many outcomes the results were based on only one trial. Reduction of MBL in two of the nine trials (Cameron 1987; Hall 1987) that were included in the metaanalysis was correctly reported as a median and range in the publications since the distribution of data was positively skewed with one or more extremely high values. Substitution of the mean for the median and the estimation of the standard deviation for these studies has enabled their inclusion in the meta-analysis but sensitivity analysis with and without the inclusion of the Cameron trial has not altered results. The Hall study was the only trial comparing MBL after treatment with two NSAIDs, mefenamic acid and naproxen. The Mann-Whitney $U$ test reported in the publication of the trial agreed with the results of the meta-analysis finding no significant difference between the groups.

Two of the included trials had incomparable groups at baseline (Chamberlain 1991; Cameron 1987) but sensitivity analysis indicated that their inclusion in the meta-analysis did not substantially alter the results.

Assessments of carryover effects were made in two trials (Fraser 1981; Hall 1987). Fraser found in his crossover trial of mefenamic acid and placebo, somewhat surprisingly, that the MBL during placebo cycles was greater (but not significantly) in the group that took mefenamic acid first. Of considerable interest was the finding that blood loss in the mefenamic acid cycles was significantly less $(p<0.01)$ when placebo was taken first, so that mefenamic acid appeared to have a greater beneficial effect when taken after placebo. There was evidence of a small carryover effect but this did not reach statistical significance. Hall also tested for carryover effects but none were found ( $\mathrm{p}=0.96)$. It is generally accepted that menstrual blood loss returns to baseline levels very quickly after medical treatment is withdrawn and so the results from the crossover trials were unlikely to be affected by carryover effects.

In spite of the limited data, it appears that NSAIDs are more effective than placebo but less effective than tranexamic acid or danazol in reducing heavy menstrual bleeding. However, adverse events are more frequent under danazol therapy than NSAID therapy.

\section{AUTHORS' CONCLUSIONS}

\section{Implications for practice}

The review provides limited evidence of the efficacy of NSAIDs (of which the most commonly studied is mefenamic acid) as a treatment for reducing heavy menstrual bleeding in women with menorrhagia. The efficacy of NSAIDs, however is superseded by both danazol and tranexamic acid. Other medical treatments appear to be similarly effective compared to NSAIDs, although there is a suggestion that mefenamic acid may be more effective than either ethamsylate or oral progestogen. Danazol also reduces the number of days of menstrual bleeding but is more likely to cause adverse events when compared to NSAIDs. Gastro-intestinal ef- 
fects, which are often found with NSAID treatment, are less likely with mefenamic acid than naproxen.

It is important to emphasize that a proportion of women with a convincing history of menorrhagia may not have excessive bleeding as defined by the alkaline haematin method. Treatments used to reduce blood loss in these women are not likely to be as effective.

The results of the review underscore the multiple assessments that are required in the evaluation of an optimum treatment. Efficacy is only one of these; other factors such as cost, convenience, beneficial and adverse effects on symptoms are also required.

\section{Implications for research}

Since mefenamic acid has been most commonly studied, further RCTs are required to compare individual NSAIDs so that the optimum treatment can be identified. One of the excluded trials (Vargyas 1987) reported a greater percentage reduction from baseline MBL in women using another fenamate, meclofenamic acid, when compared to other studies assessing mefenamic acid.

Because many of the analyses contained only one RCT, some of the comparisons were not able to be assessed thoroughly, in particular, the effects of NSAIDs on dysmenorrhoea, adherence to and acceptability of treatment and incidence of adverse events. However, since NSAIDs are less efficacious than a number of other medical therapies, further RCTs are not likely to significantly change the findings in this review. Future studies comparing treatments for heavy menstrual bleeding should consider giving a longer duration of treatment over a number of cycles and a regimen of oral progestogen given during three of the four weeks of the cycle to adequately assess comparative effects between medical treatments.

\section{ACKNOWLEDGEMENTS}

The authors acknowledge the helpful comments of those who refereed previous versions of this review. Special thanks are due to Ms Ruth Jepson, Review Group Coordinator, for her professionalism and help with the inevitable problems that arise, to Mrs Sue Furness, Trials Search Coordinator, for her assistance with identifying trials and to Mrs Sue Hall, Secretary of the Review Group, for her secretarial help. The authors would also like to acknowledge the input of the Consumer Network who wrote a synopsis for the review. This synopsis has been added by the principal author with minor editing.

\section{REF ER E N C E S}

\section{References to studies included in this review}

\section{Andersch 1988 \{published data only\}}

* Andersch B, Milsom I, Rybo G. An objective evaluation of flurbiprofen and tranexamic acid in the treatment of idiopathic menorrhagia. Acta Obstetricia et Gynecologica Scandinavica 1988;67:645-48.

Milsom I, Andersson K, Andersch B, Rybo G. A comparison of flurbiprofen, tranexamic acid, and a levonorgestrelreleasing intrauterine contraceptive device in the treatment of idiopathic menorrhagia. American Journal of Obstetrics and Gynecology 1991;164:879-883.

Bonnar 1996 \{published data only\}

Bonnar J, Sheppard BL. Treatment of menorrhagia during menstruation: randomised controlled trial of ethamsylate, mefenamic acid, and tranexamic acid. BMJ 1996;313: 579-582.

Cameron 1987 \{published data only\}

Cameron IT. Dysfunctional uterine bleeding. Bailliere's Clinical Obstetrics and Gynaecology 1989;2:315-327.

* Cameron IT, Leask R, Kelly RW, Baird DT. The effects of danazol, mefenamic acid, norethisterone and a progesterone-impregnated coil on endometrial prostaglandin concentrations in women with menorrhagia. Prostaglandins 1987;34:99-110.
Cameron 1990 \{published data only\}

* Cameron IT, Haining R, Lumsden MA, Thomas VR, Smith SK. The effects of mefenamic acid and norethisterone on measured menstrual blood loss. Obstetetrics \& Gynecology 1990;76:85-88.

Smith SK, Haining RH, Reed-Thomas V, Cameron IT. The diagnosis and treatment of menorrhagia (abstract). Silver Jubilee British Congress of Obstetrics and Gynaecology 1989:62.

Chamberlain 1991 \{published and unpublished data\} Chamberlain G. Comparing treatments for menorrhagia. Nursing Times 1992;88:46.

Chamberlain G, Freeman R, Price F, Kennedy A, Green D, Eve L. A comparative study of ethamsylate and mefenamic acid in dysfunctional uterine bleeding. British Journal of Obstetrics and Gynaecology 1991;98:707-711.

* Chamberlain G, Freeman R, Price F, Kennedy A, Green D, Eve L. Raw data from RCT. Lorex Synthelabo Laboratory in UK.

Dockeray 1989 \{published data only\}

Dockeray CJ, Sheppard BL, Bonnar J. Comparison between mefenamic acid and danazol in the treatment of established menorrhagia. BrJ Obstets Gynaecol 1989;96:840-844.

Fraser 1981 \{published data only\}

Fraser IS, Pearse C, Shearman RP, Elliott PM, McIlveen J, Markham R. Efficacy of mefenamic acid in patients with 
a complaint of menorrhagia. Obstets Gynaecol 1981;58(5): 543-551.

Fraser 1991 \{published data only\}

Fraser IS, McCarron G. Randomised trial of 2 hormonal and 2 prostaglandin-inhibiting agents in women with a complaint of menorrhagia. Aust NZJ Obstet Gynaecol 1991; 31(1):66-70.

\section{Grover 1990 \{published data only\}}

Grover V, Usha R, Gupta U, Kalra S. Management of cyclical menorrhagia with prostaglandin synthetase inhibitor. Asia-Oceania J Obstet Gynaecol 1990;16:255-259.

Hall 1987 \{published data only\}

Hall P, MacLachlan N, Thorn N, Nudd MWE, Taylor CG, Garrioch DB. Control of menorrhagia by the cyclooxygenase inhibitors naproxen sodium and mefenamic acid. Brit J Obstet Gynaecol 1987;94:554-558.

Makarainen 1986 \{published data only\} Makarainen L, Ylikorkala O. Primary and myomaassociated menorrhagia: role of prostaglandin and effects of ibuprofen. Brit J Obstet Gynaecol 1986;93:974-978.

Muggeridge 1983 \{published data only\}

Muggeridge J, Elder MG. Mefenamic acid in the treatment of menorrhagia. Res Clin Forums 1983;5:83-88.

Rybo 1981 \{published data only\}

Nygren KG, Rybo G. Prostaglandins and menorrhagia. Acta Obstet Gynecol Scand Suppl 1983;113:101-103.

* Rybo G, Nilsson S, Sikstrom B, Nygren KG. Naproxen in menorrhagia (letter). Lancet 1981;March:608-609.

Tsang 1987 \{published data only\}

Tsang BK, Domingo MT, Spence JEH, Garner PR, Dudley DK, Oxorn H. Endometrial prostaglandins and menorrhagia: influence of a prostaglandin synthetase inhibitor in vivo. Can J Physiol Pharmacol 1987;65: 2081-2084.

van Eijkeren 1992 \{published data only\} van Eijkeren MA, Christiaens GCML, Geuze HJ, Haspels AA, Sixma JJ. Effects of mefenamic acid on menstrual hemostasis in essential menorrhagia. Am J Obstet Gynecol 1992;166:1419-28

Ylikorkala 1986 \{published data only\}

Ylikorkala O, Pekonen F. Naproxen reduces idiopathic but not fibromyoma-induced menorrhagia. Obstets Gynaecol 1986;68:10-12.

\section{References to studies excluded from this review}

\section{Martinez 1979}

* Martinez Alcala FO, Casanova Alvarez N, Manzanilla Sevilla R, Gonzalez Iniguez R, Martinez Reyes y P. Efficacy and tolerability of mefenamic acid in dysfunctional uterine bleeding [Eficacia y tolerabilidad del acido mefenamico en la hipermenorrea disfuncional]. Prensa Med Mex 1979;44 (11-12):295-98.
Vargyas 1987

Vargyas JM, Campeau JD, Mishell DR. Treatment of menorrhagia with meclofenamate sodium. Am J Obstet Gynecol 1987;157:944-50.

\section{Additional references}

\section{Anderson 1976}

Anderson AB, Haynes PJ, Guillebaud J, Turnbull AC. Reduction of menstrual blood-loss by prostaglandinsynthetase inhibitors. Lancet 1976;1(7963):774-6.

Bradlow 1992

Bradlow J, Coulter A, Brooks P. Patterns of referral. Oxford: Oxford Health Services Research Unit, 1992.

\section{Chimbira 1980}

Chimbira TH, Anderson ABM, Turnbull AC. Relation between measured menstrual blood loss and patient's subjective assessment of loss, duration of bleeding, number of sanitary towels used, uterine weight and endometrial surface area. Br J Obstet Gynaecol 1980;87:603-609.

Clarke 1995

Clarke A, Black N, Rowe P, Mott S, Howie K. Indications for and outcomes of total abdominal hysterectomy for benign disease: a prospective cohort study. $\mathrm{Br} \mathrm{J} \mathrm{Obstet}$ Gynaecol 1995;102:611-20.

Cole 1971

Cole S, Billewicz W, Thomson A. Sources of variation in menstrual blood loss. J Obstet Gynaecol Brit Commonw 1971;78(10):933-39.

Fraser 1981

Fraser IS, Pearse C, Shearman RP, Elliott PM, McIlveen J, Markham R. Efficacy of mefenamic acid in patients with a complaint of menorrhagia. Obstets Gynecol 1981;58: 543-551.

Fraser 1983

Fraser IS, McCarron G, Markham R, Robinson M, Smyth E. Long term treatment of menorrhagia with mefenamic acid. Obstet Gynaecol 1983;61:109-112.

Fraser 1984

Fraser IS, McCarron G, Markham R. A preliminary study of factors influencing perception of menstrual blood loss volume. Am J Obstet Gynecol 1984;149:788-793.

Gath 1982

Gath D, Cooper P, Day A. Hysterectomy and psychiatric disorder. Levels of psychiatric morbidity before and after hysterectomy. Int J Psych 1982;140:335-340.

\section{Hagenfeldt 1987}

Hagenfeldt K. The role of prostaglandins and allied substances in uterine haemostasis. Contraception 1987;36 (1):23-35.

\section{Hallberg 1966}

Hallberg L, Hogdahl AM, Nilsson L, Rybo G. Menstrual blood loss - a population study. Acta Obstet Gynecol Scand 1966;45:320-351. 
Haynes 1977

Haynes PJ, Hodgson H, Anderson AB, Turnbull AC. Measurement of menstrual blood loss in patients complaining of menorrhagia. Br J Obstet Gynaecol 1977;84 (10):763-8.

Higham 1990

Higham JM, O'Brien PMS, Shaw RW. Assessment of menstrual blood loss using a pictorial chart. Br J Obstet Gynaecol 1990;97:734-39.

Newton 1977

Newton J, Barnard G, Collins W. A rapi method for measuring menstrual blood loss using automatic extraction. Contraception 1977;16:269-82.

Rees 1987

Rees MCP, DiMarzo V, Tippins JR, et al.Leukotriene release by endometrium and myometrium throughout the menstrual cycle in dysmenorrhoea and menorrhagia. $J$ Endocrinol 1987;113:291-5.
Smith 1981

Smith SK, Abel MH, Kelly RW, Baird DT. Prostaglandin synthesis in the endometrium of women with ovular dysfunctional uterine bleeding. Br J Obstet Gynaecol 1981; 88:434-442.

Vessey 1992

Vessey M, Villard-Mackintosh L, McPherson K, Coulter A, Yeates D. The epidemiology of hysterectomy: findings in a large cohort study. Br J Obstet Gynaecol 1992;99(5):402-7.

Willman 1976

Willman EA, Collins WD, Clayton SC. Studies on the involvement of prostaglandins in uterine symptomatology and pathology. Br J Obstet Gynaecol 1976;83:337-341.

\section{Wood 1980}

Wood C, Jakubowicz D. The treatment of premenstrual symptoms with mefenamic acid. Br J Obstet Gynaecol 1980; 87(7):627-30.

* Indicates the major publication for the study

\section{SOURCES OF SUPPORT}

\section{External sources of support}

- Heatlth Research Council, Auckland NEW ZEALAND

\section{Internal sources of support}

- Department of Obstetrics and Gynaecology, University of Auckland, Auckland NEW ZEALAND

\section{NOTES}

An updated search was performed in September and October 2001 but no new eligible trials were identified.

\section{NDEX TERMS}

\section{Medical Subject Headings (MeSH)}

Anti-Inflammatory Agents, Non-Steroidal [*therapeutic use]; Dysmenorrhea [drug therapy]; Menorrhagia [* drug therapy]; Randomized Controlled Trials 


\section{MeSH check words}

Female; Humans 